Article

\title{
HiPIMS and DC Magnetron Sputter-Coated Silver Films for High-Temperature Durable Reflectors
}

\author{
Sophie Gledhill *(1), Kevin Steyer, Charlotte Weiss and Christina Hildebrandt \\ Fraunhofer Institute for Solar Energy Systems, Heidenhofstraße 2, 79110 Freiburg, Germany; \\ kevin.steyer@ise.fraunhofer.de (K.S.); charlotte.weiss@ise.fraunhofer.de (C.W.); \\ christina.hildebrandt@ise.fraunhofer.de (C.H.) \\ * Correspondence: sophie.gledhill@ise.fraunhofer.de; Tel.: +49-761-4558-2049
}

Received: 10 July 2019; Accepted: 17 September 2019; Published: 20 September 2019

check for updates

\begin{abstract}
High-temperature durable mirrors based on a protected silver sputter coating are attractive for secondary reflector applications in concentrated solar thermal power plants. In this paper, silver films are deposited by high-power impulse magnetron sputtering (HiPIMS) and standard direct current (DC) magnetron sputtering, either as exposed discretely deposited films or in-sequence-deposited thin film systems, where the silver is protected and embedded between adhesion and barrier layers. The unprotected silver films and equivalent protected silver thin film systems are compared and characterized as deposited and after $400{ }^{\circ} \mathrm{C}$ oven temperature exposure. The reflectance is measured and grazing incident X-ray diffraction (GIXRD) and scanning electron microscopy (SEM) pictures were taken. The HiPIMS silver film, sputtered with a peak current of $200 \mathrm{~A}$ and an approximately equivalent average power density to the DC magnetron sputtered silver, exhibits higher reflectance (and conductivity). Increasing the power density further, yields silver films with lower reflectance, correlating to a reduced grain size. In the protected silver film system, the reflectance does not improve, due to the presence of a less reflective top adhesion layer. The protected film system, with the 200 A HiPIMS, is, however, more durable at $400{ }^{\circ} \mathrm{C}$ than the DC magnetron sputtered equivalent.
\end{abstract}

Keywords: protected silver; secondary reflector; sputtering; HiPIMS; GIXRD; thin film

\section{Introduction}

Concentrated solar power (CSP) systems generate solar power by using mirrors or lenses (primary concentrators or reflectors) to concentrate a large area of sunlight, or solar thermal energy, onto a smaller area (the receiver). A secondary concentrator reflects the sunlight coming from the primary concentrators onto the absorbing receiver. They ensure the gathering and redirecting, and in some applications further concentration and focusing, of the solar beams towards the absorber. A good overview of the available different secondary reflector material systems and different CSP configurations is given in [1].

A secondary reflector which is installed adjacent to the solar tower or linear Fresnel collector receiver can improve the optical efficiency of the system considerably as well as reducing its cost by [2]:

- Reducing the amount of flux which is spilled-off the target

- Improving the flux distribution uniformity

- Decreasing heat losses and CAPEX (capital expenditure) by reducing the receiver size

The main challenge for such a mirror is its high operation temperature. For the solar power tower, the high temperatures evolve mainly due to the amount of irradiance that is being absorbed by the mirror, and to a lesser extent due to convective heat exchange with its surrounding. One possible 
approach is to water-cool the mirror. However, this solution will mean an investment increase, technical challenges, and cause a plant shut-down in case of any failure of the cooling system.

A different approach avoiding water-cooling was to develop a protected silver coated secondary mirror which could retain its optical and mechanical properties up to $350{ }^{\circ} \mathrm{C}$. The developed mirrors are based on a sputtered silver layer and several adhesion and barrier layers on a highly polished steel substrate. The silver layers are sputtered using either standard direct current magnetron sputtering (DC MS) or, alternatively, high-power impulse magnetron sputtering (HiPIMS) [3]. With HiPIMS, high power (up to megawatt range) is applied to the magnetron target in unipolar pulses at a low duty cycle and low repetition frequency while keeping the average power about two orders of magnitude lower than the peak power. This results in a high plasma density and high ionization fraction of the sputtered vapor. Previous studies with silver HiPIMS layers show an improvement in electrical conductance attributed to atomically smoother and denser films [4,5] being grown from the high energy flux of the sputtered silver.

For protected silver coatings for reflector applications, a desired improvement in both reflectance and film stability was the motivation to investigate HiPIMS silver in comparison to the standard DC MS silver. As the silver films must be durable at high temperature, the films were examined (optically and micro-structurally) as deposited and after exposure to a temperature of $400{ }^{\circ} \mathrm{C}$ (plausible operational conditions for the stringent solar power tower reflector). It should be noted that the protected silver coatings were tested under different conditions (e.g., a humidity and heat of $85 \%$ and $85^{\circ} \mathrm{C}$, respectively), but that is not the focus of the paper here. Other applications of protected sputtered silver where highly reflective yet highly durable reflector coatings are required, include telescopes (such as the coatings used at the Gemini Observatory telescope [6]) or in robust floodlight applications.

\section{Materials and Methods}

The HiPIMS and DC MS silver films were prepared in house at the Fraunhofer Insitute of Solar Energy Systems. Both processes used $99.99 \%$ pure silver targets which were sputtered in argon atmospheres of approximately $300 \mathrm{~Pa}$. A TruPlasma Highpulse 4008 DC generator (Trumpf-Hüttinger, Freiburg, Germany) was used for the HiPIMS mode. The DC magnetron was powered by a TIG-DCS (Trumpf-Hüttinger, Freiburg, Germany). The electrical sputter parameters for the DC MS and HiPIMS silver are given in Table 1. For HiPIMS deposition, a pulse frequency of $150 \mathrm{~s}^{-1}$ and pulse duration of $80 \mu$ s was used.

Table 1. Electrical sputter parameters used to produce the silver layers. The parameters given in bold correlate with the conditions used to prepare both the discrete silver layer and the embedded silver film in the protected silver layer system. The approximate peak power density $\left(P_{\text {peak }}\right)$ and the average power density $(P$ average $)$ are given here. The dynamic deposition rate is given as is and normalized to the power density.

\begin{tabular}{|c|c|c|c|c|c|}
\hline $\begin{array}{c}\text { Target Power } \\
\text { Delivery Mode }\end{array}$ & $\frac{\text { I }}{(A)^{1}}$ & $\begin{array}{c}P_{\text {peak }} \\
\left(\mathrm{W} \cdot \mathrm{cm}^{-2}\right)\end{array}$ & $\begin{array}{c}P_{\text {average }} \\
\left(\mathrm{W} \cdot \mathrm{cm}^{-2}\right)\end{array}$ & $\begin{array}{c}\text { Dynamic } \\
\text { Deposition } \\
\text { Rate } \\
\left(\mathrm{nm} \cdot\left(\mathrm{m} \mathrm{min}^{-1}\right)\right)\end{array}$ & $\begin{array}{c}\text { Dynamic Power Density } \\
\text { Normalized Deposition Rate } \\
\left(\mathrm{nm} \cdot\left(\mathrm{m} \mathrm{min}^{-1}\right)\right. \\
\left.\left(\mathrm{kW} \mathrm{m}^{-2}\right)^{-1}\right)\end{array}$ \\
\hline \multirow[t]{2}{*}{ DC } & 12 & 4 & 4 & 66 & 1.65 \\
\hline & 100 & 192 & 2.3 & 21 & 0.91 \\
\hline \multirow{3}{*}{ HiPIMS } & 200 & 320 & 3.8 & 27 & 0.71 \\
\hline & 300 & 621 & 7.4 & 47 & 0.61 \\
\hline & 400 & 1005 & 12.1 & 67 & 0.55 \\
\hline
\end{tabular}

${ }^{1}$ This is the peak current for the HiPIMS, the constant current in DC MS mode.

A current of $12 \mathrm{~A}$ in the DC magnetron mode was chosen, as this was the standard silver used in the protected silver system. It exhibits the highest temperature durability for DC magnetron mode. The 200 A HiPIMS silver was deposited with a similar power density to the 12 A DC MS sample. 
The power density is given only as an approximate value, as it is calculated from the power and the approximate race-track area of the silver target magnetron. The measured dynamic rate, normalized to the power density, is given in Table 1. As typically seen, HiPIMS mode led to a drop in the deposition rate for equivalent power density. This is caused by increased film density, increased self-sputtering, and sputtering of the film at higher peak currents, as discussed in [7].

Cleaned float glass was used as a substrate for reflectance and conductivity measurements. Glass with a sputtered $45 \mathrm{~nm} \mathrm{NiCr}$ ( $\mathrm{Ni}: \mathrm{Cr}$ 80:20 wt \% target DC magnetron, $9.5 \mathrm{~W} / \mathrm{cm}^{2}$ in an Ar pressure of $0.16 \mathrm{~Pa}$ ) adhesion layer was used as a substrate for the reflectance, grazing incidence $\mathrm{X}$-ray diffraction (GIXRD), and scanning electron microscopy (SEM) analysis. It should be noted that for the SEM and GIXRD measurements, the adhesion layer coating which the silver is sputtered on was identical for both the discrete and the protected silver.

The protected silver layer system was deposited also on polished $1 \mathrm{~mm} 1.4301$ steel substrates. The protected sputtered silver system was $\mathrm{NiCr}(45 \mathrm{~nm}) / \mathrm{Ag}(120 \mathrm{~nm}) / \mathrm{NiCr}(0.5 \mathrm{~nm}) / \mathrm{Si}_{\mathrm{x}} \mathrm{N}_{\mathrm{y}}(100 \mathrm{~nm})$ and is shown in Figure 1. The $\mathrm{Si}_{\mathrm{x}} \mathrm{N}_{\mathrm{y}}$ barrier and $\mathrm{NiCr}$ adhesion layers were sputtered in sequence with the silver films. The bottom NiCr layer was as described above. The top $\mathrm{NiCr}$ layer used a standard DC planar magnetron (target Ni:Cr 80:20 wt \%) with a power of $0.8 \mathrm{~W} / \mathrm{cm}^{2}$ in an Ar atmosphere of pressure $0.09 \mathrm{~Pa}$. The $\mathrm{Si}_{\mathrm{x}} \mathrm{N}_{\mathrm{y}}$ was deposited using a middle frequency, $\mathrm{MF}$, dual rotary cathode (target Si:Al 90:10 wt \%) at $10.8 \mathrm{~W} / \mathrm{cm}^{2}$ in an Ar/N2 (gas flow rate ratio 1:1) at a pressure of $0.3 \mathrm{~Pa}$. The top adhesion was a nominal $0.5 \mathrm{~nm} \mathrm{NiCr}$ designed to maximize the Ag-to-barrier layer adhesion with minimal reflectance degradation.

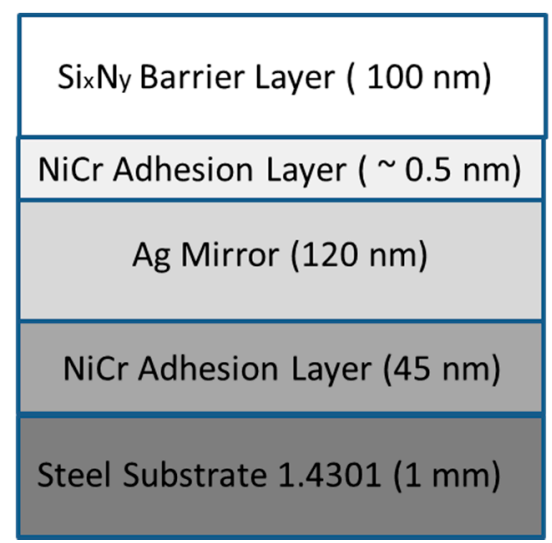

Figure 1. Schematic of the protected silver layer system.

All GIXRD patterns were recorded using a Philips X'Pert MRD system equipped with a $\mathrm{CuK}_{\alpha}$ X-ray source. The Scherrer [8] formula,

$$
\tau=\frac{K \lambda}{\beta \cos \theta}
$$

was used as a comparative empirical guide (where $\tau$ is the grain size; $K$ is a shape factor, here with a value of $0.9 ; \lambda$ is the X-ray wavelength of $1.54 \AA$; $\beta$ is the full width half maximum; and $\theta$ is the Bragg angle), rather than an accurate calculation of the average grain size. The shifts in peak position with annealing were estimated and compared, again to determine a trend between samples rather than a precise measurement of strain in the silver crystal lattice.

The scanning electron microscope used was a FIB-SEM Auriga 60 (Zeiss, Oberkochen, Germany). Reflectance measurements were done with a Vertex 80 spectrometer (Bruker, Ettlingen, Germany) with an integrated sphere. The solar hemispherical reflectance is the percentage of the direct and diffuse AM1.5 solar radiance reflected from the coating system. Sheet resistance measurements were taken with a four-point probe (only for pure silver-coated glass substrates). The conductivity was thus calculated from the measured film thickness. Sputtered film thickness was checked using both 
a Dektak 6M profilmeter (Veeco, New York, NY, USA) and a calibrated Xray Fluorescence Spectrometer, XRF, Fischerscope XDV- $\mu$ (Helmut-Fischer, Sindelfingen, Germany).

\section{Results}

The results section is divided into two subsections for clarity. Firstly, the results for the discrete silver films are presented, and secondly, the results for the protected silver film system are given.

\subsection{Discrete Silver Films}

The discrete silver thin films were investigated in addition to the protected silver film system, as having no top coatings allows for a deeper understanding of the silver layers themselves.

The reflectance spectra of the as-deposited discrete $500 \mathrm{~nm}$ silver films on glass substrates are presented in Figure 2a. The solar reflectance increased to a maximum for the silver films deposited with $200 \mathrm{~A}$ in HiPIMS mode, but for higher HiPIMS currents it decreased and, indeed, with $400 \mathrm{~A}$ HiPIMS it was lower than the 12 A DC MS-deposited silver film. In Figure $2 b$, the conductivity of the films is plotted against the global solar hemispherical reflectance. The films sputtered by HiPIMS exhibit an approximately linear relationship whereby the conductivity proportionally increases with increasing reflectance. The 12 A DC MS samples are sputtered in a different mode and exhibit a higher conductivity-to-reflectance ratio than the HiPIMS films.

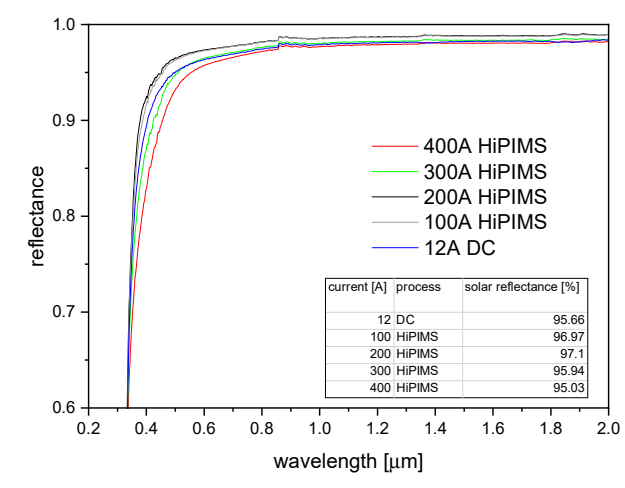

(a)

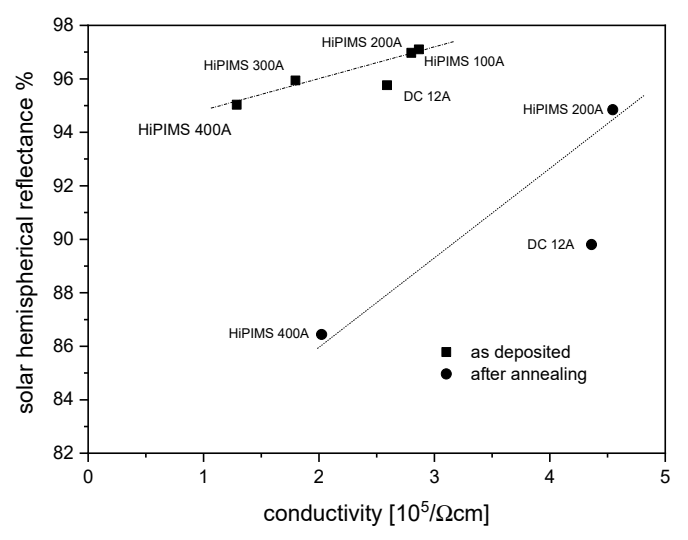

(b)

Figure 2. (a) Reflectance spectrum of the discrete $500 \mathrm{~nm}$ silver films sputtered on glass substrates with different currents (direct current (DC) and high-power impulse magnetron sputtering (HiPIMS) mode). The embedded table shows the global solar (AM 1.5 radiance) hemispherical reflectance for the silver films sputtered with different parameters. (b) Silver film conductivity against global solar hemispherical reflectance (500 nm silver on glass), both as deposited and after annealing for $8 \mathrm{~h}$ at $400{ }^{\circ} \mathrm{C}$. The dotted lines serve only as a guide to the eye.

The films were annealed at $400{ }^{\circ} \mathrm{C}$ for $0.5,4,8,16$, and $32 \mathrm{~h}$, the reflectance and conductivity were subsequently measured. With increasing annealing time, the conductivity of all the silver films increased, but solar reflectance decreased. What is more, the reflectance changed from being purely specular to partially diffuse. After $8 \mathrm{~h}$ annealing at $400{ }^{\circ} \mathrm{C}$, corresponding to the data shown in Figure $2 \mathrm{~b}$, the 200 A HiPIMS silver films remained highly reflective ( $94 \%$ total) but the diffuse solar reflectance contribution was $40 \%$, whilst the 12 A DC MS silver and the highly energetically sputtered 400 A HiPIMS silver had a lower total reflectance ( $89 \%$ and $84 \%$, respectively) but also a lower diffuse contribution (10\% and $2 \%$, respectively). Due to this high optical scattering, the 200 A HiPIMS films appeared white after annealing.

SEM pictures are shown in Figure 3 of equivalent $120 \mathrm{~nm}$ silver films grown on the $\mathrm{NiCr}$-coated glass. The as-deposited films appeared smooth and relatively featureless at low magnification. The grains, observable at high magnification, for the 12 A DC MS silver and the 200 A HiPIMS silver were apparently 
of a similar size ( $\leq 20 \mathrm{~nm}$ ), whereas the 400 A HiPIMS grains were distinguishably smaller $(\leq 10 \mathrm{~nm})$. After annealing (again for $8 \mathrm{~h}$ at $400{ }^{\circ} \mathrm{C}$ ), all samples exhibited the characteristic agglomeration (large crystals) and hole (void) formation of unprotected silver exposed to elevated temperatures reported in [9]. Moreover, the grain growth in the bulk of the film was apparent for all samples. The average bulk grains, post annealing, for the 200 A HiPIMS appeared the largest $(50-150 \mathrm{~nm})$, whilst the 400 A HiPIMS appeared the smallest $(10-50 \mathrm{~nm})$.

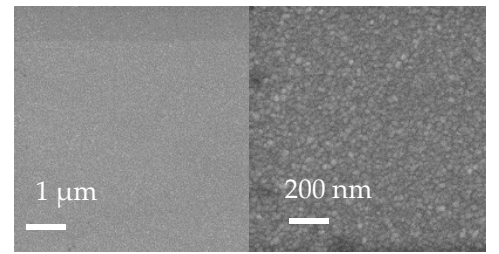

(a)

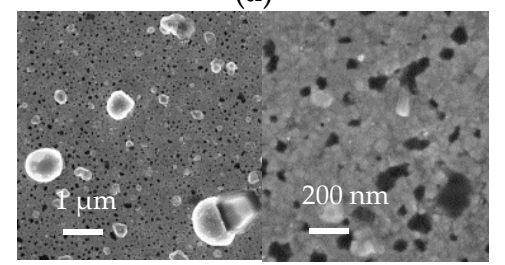

(d)



(b)

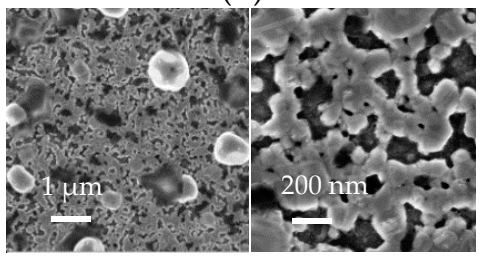

(e)

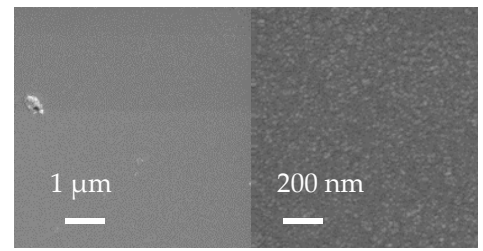

(c)

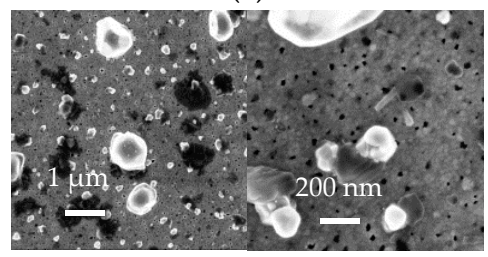

(f)

Figure 3. Scanning electron microscopy (SEM) pictures. Each picture pair is from the same sample, the one on the right being of higher magnification than the one on the left. The scale is given in (a). (a-c) The upper pictures show the films as deposited after sputtering, whilst (d-f) shows pictures post $8 \mathrm{~h}$ anneal at $400{ }^{\circ} \mathrm{C} ;(\mathbf{a}, \mathbf{d})$ shows the 12 A direct current magnetron sputtering (DC MS) silver; (b,e) shows the 200 A HiPIMS silver; and (c,f) shows the 400 A HiPIMS silver.

It is clear from the SEM pictures that the smooth silver films became significantly rougher, caused by the agglomeration and voiding $[9,10]$. This can be correlated with the decrease in spectral and total solar reflectance. The rougher surface features would cause the observed pronounced scattering despite the increased grain size, with annealing, which allows the conductivity to improve, provided the film remains networked.

In Figure 4a, the GIXRD spectra for the 400 A HiPIMS, 200 A HiPIMS, and 12 A DC MS silver films deposited on $\mathrm{NiCr}$ coated glass substrates, as-deposited and after an $8 \mathrm{~h}$ anneal at $400{ }^{\circ} \mathrm{C}$, are shown. As stated, the grain size, peak position and intensity were calculated or measured from the spectra, and for clarity and transparency they are given in Table $\mathrm{S} 1$ as supplementary material.

Randomly oriented polycrystalline silver has a diffraction peak ratio of (111):(200):(220):(311):(222) as 100:40:25:26:12 [11]. In all as-deposited films sputtered here, the (220) plane exhibited a larger relative intensity than the random oriented reference.

After annealing, the diffraction from the (220) plane had the highest intensity, and the relative contribution from the (111) planes reduced significantly as the grains increased in orientation. This is particularly pronounced in the 200A HiPIMS silver film.

Using the Scherrer formula as a qualitative indication of grain size, it is implicated that for the as-deposited samples, the $200 \mathrm{~A}$ HiPIMS silver film has marginally larger grains than the $12 \mathrm{~A}$ DC MS silver film, but the 400 A HiPIMS silver film has grains smaller in size. This correlates with what is seen in the SEM pictures. It can be also correlated to the trend in conductivity of the silver film on the glass substrate: a smaller grain size yields lower sheet conductivity. There is no clear peak shift on annealing, although the observed narrowing of the peaks with annealing indicates grain growth in the sample, again in correlation with the SEM pictures and the increase in conductivity with annealing in equivalent films. Figure $4 \mathrm{~b}$ is discussed in the context of the next section. 




(a)
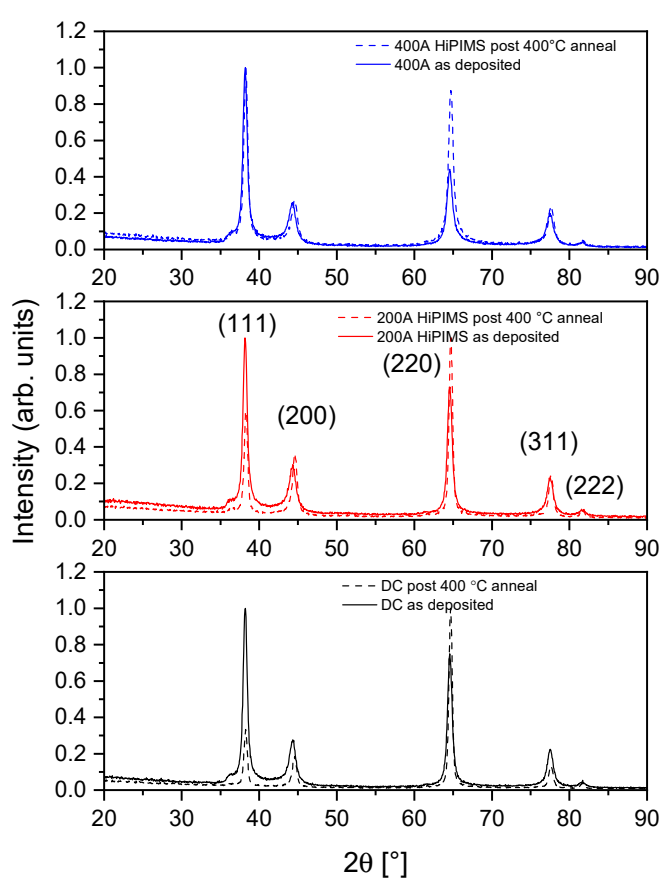

(b)

Figure 4. Grazing incident X-ray diffraction (GIXRD) for the 400 A HiPIMS, 200 A HiPIMS, and 12 A DC MS $120 \mathrm{~nm}$ sputtered silver (a) as discrete films on coated-glass substrates as deposited and after $8 \mathrm{~h}$ anneal at $400^{\circ} \mathrm{C} ;(\mathbf{b})$ as protected silver coating systems on glass substrates, as deposited (solid line), and after $24 \mathrm{~h}$ anneal at $400{ }^{\circ} \mathrm{C}$. The adhesion layer underneath the silver is identical in both cases for the GIXRD measurements.

\subsection{Protected Silver Thin Film System}

In this section, the results of the protected silver thin film systems will be presented.

GIXRD spectra shown in Figure $4 \mathrm{~b}$ for the 400 A HiPIMS, 200 A HiPIMS, and 12 A DC MS protected silver film system deposited on coated glass substrates are shown as deposited and after a $24 \mathrm{~h}$ anneal at $400{ }^{\circ} \mathrm{C}$. Glass substrates were used for the GIXRD to avoid any interference diffraction peaks from the underlying steel substrate. Both the discrete silver discussed earlier and the protected silver system were grown on the same $45 \mathrm{~nm} \mathrm{NiCr}$ adhesion layer coating the glass. The difference was that the protected silver system had a top $\mathrm{NiCr}$ adhesion and $\mathrm{Si}_{\mathrm{x}} \mathrm{N}_{\mathrm{y}}$ barrier coating. As previously, the grain size, peak position, and intensity were calculated or measured from the spectra, and for clarity and transparency they are given in Table S2 as supplementary material. The as-deposited protected silver films exhibit the same trend in grain sizes as the as-deposited discrete silver films, and the grains are likewise orientated. After the $24 \mathrm{~h}$ anneal at $400{ }^{\circ} \mathrm{C}$, the grains were larger and became even more aligned, with the (111) peak reducing and the (220) peak increasing in amplitude. What is different from the discrete silver films is that after annealing the protected silver films, there was a clear peak shift to a higher Bragg angle. The average peak shift was higher in the HiPIMS films than in the DC MS film. This is an indication that the silver protected film is compressively strained after the annealing step.

Figure 5 a shows the global reflectance of the as-deposited protected silver thin films systems. The total solar reflectance of all the film systems was reduced to below $90 \%$. In this case here, the top adhesion layer was an ultra-thin $\mathrm{NiCr}$ deposition (nominally $0.5 \mathrm{~nm}$ thick, in practice an incomplete covering). Adding additional layers, such as the $\mathrm{Si}_{\mathrm{x}} \mathrm{N}_{\mathrm{y}}$ barrier layer, on top of the silver film reduced the total reflectance due to unwanted interference from additional interfacial reflectance and absorption by the adhesion and barrier layer. This was particularly prevalent in the UV-visible portion of the spectrum. Due to this, the gain in reflectance that was achieved for the discrete silver by depositing 
with the 200 A HiPIMS instead of 12 A DC MS silver was not apparent. The reflectance of the film system incorporating the 400 A HiPIMS silver was however lower, which was most likely due to the poorer silver reflectance, since the film system was identical between samples.

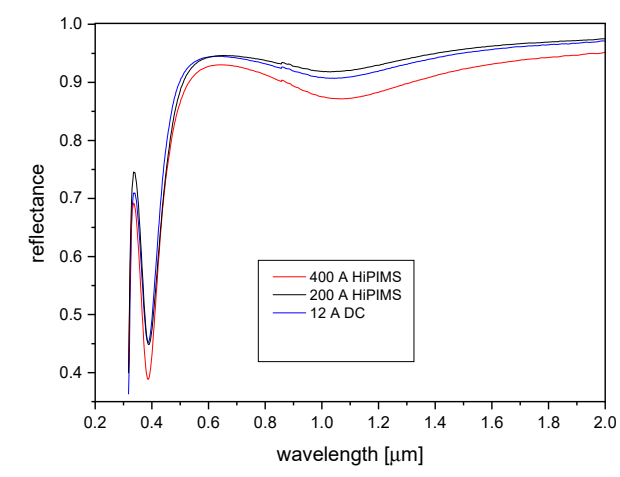

(a)

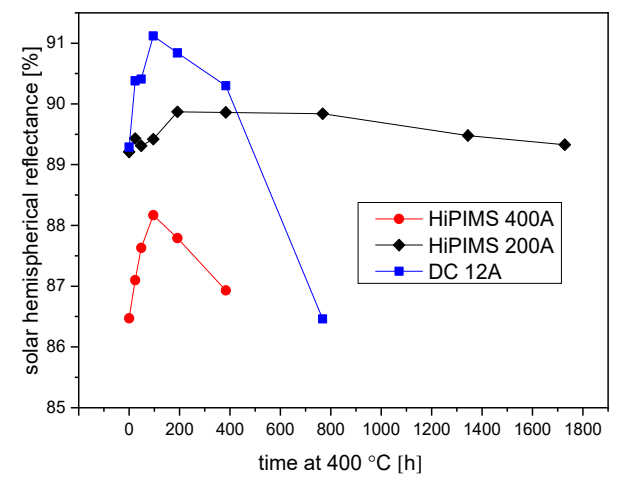

(b)

Figure 5. (a) Reflectance spectrum of the protected silver layer system (as deposited) on steel substrates for the three alternative silver deposition conditions; (b) Global solar hemispherical reflectance plotted against time in the oven at $400{ }^{\circ} \mathrm{C}$.

The protected silver thin film systems were subsequently annealed at two-fold increasing intervals, e.g., 24, 48, 96, 192, and $384 \mathrm{~h}$, until the sample was deemed to have degraded, either due to degradation apparent to the eye or a loss in optical reflectance below the starting value. The silver, being embedded in the adhesion and barrier layers, was protected from corroding elements in the atmosphere as well as agglomeration. Agglomeration, which began instantaneously at $400{ }^{\circ} \mathrm{C}$ for the discrete silver films, was limited in the protected silver system by the adhesion layers and barrier layers. For the first $96 \mathrm{~h}$ of oven time, all the silver film systems increased in reflectance. This can be partially attributed to grain growth in the silver. This occurred in the protected silver system without surface roughening due to pronounced agglomeration, which caused the optical scattering observed in the discrete silver films. The increase in reflectance may also be due to the oxidation of the top metallic adhesion layer above the silver, which subsequently exhibited a higher transmission, particularly in the UV-visible portion of the spectrum. The increase in the 12 A DC MS and 400 HiPIMS silver film systems on annealing was a $2 \%$ absolute rise in reflectance, whereas the 200 A HiPIMS silver system increased by less than $1 \%$.

After more than $96 \mathrm{~h}$ of exposure, the reflectance either plateaued or decreased. The decrease in reflectance was because of localized agglomeration of the silver. The degradation with the temperature of the silver is dependent, not only on the sputtered silver layer but on the film system. The various degradation mechanisms of the protected silver film system are discussed elsewhere [12]. In this paper, the film systems were identical, except for the silver deposition conditions. Degradation around the edges of all samples was apparent (see Figure 6 for a photograph of the mirrors after maximal oven exposure) due to higher sideways ingression of oxygen or moisture from the sample edge. Localized discrete points of degradation appeared in the bulk of the film and expanded with increased time at $400{ }^{\circ} \mathrm{C}$. This is more pronounced in the sample prepared with the $12 \mathrm{~A}$ DC MS silver. The SEM picture in Figure 7a shows a typical degradation patch from a protected 12 A DC MS silver system sample. The silver agglomerated causing rupturing of the top barrier layer coating and thus further localized accelerated agglomeration and thus larger degradation patches with time. The large crystal on the surface was silver. It was confirmed by Energy Dispersive X-ray analysis that the crystal was silver. The mechanism of corrosion was similar for the HiPIMS silver film systems. A typical example is shown in the SEM picture in Figure $7 \mathrm{~b}$, for the 200 A HiPIMS sample after $768 \mathrm{~h}$ at $400{ }^{\circ} \mathrm{C}$. Agglomeration of the silver took place, as seen for the DC MS; however, the pronounced rupturing of 
the barrier layer was not observed; thus, the points of degradation did not expand at an accelerated rate and hence resulted in smaller degradation points.

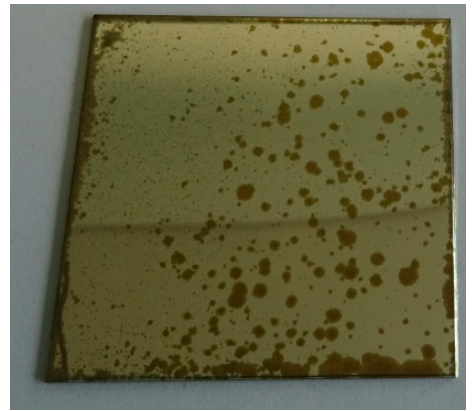

(a)

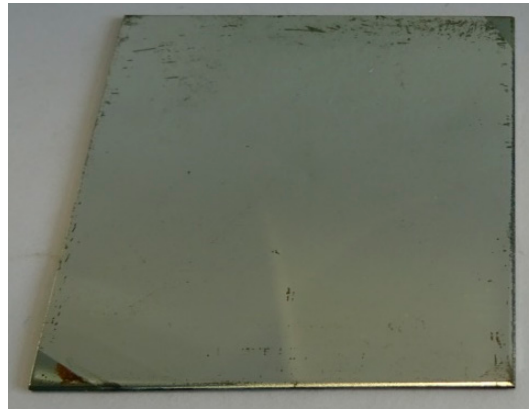

(b)

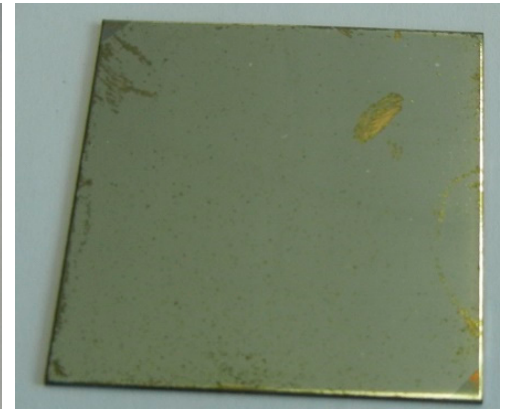

(c)

Figure 6. Photographs of $5 \times 5 \mathrm{~cm}$ protected silver coated steel after end of testing in oven at $400{ }^{\circ} \mathrm{C}$ : (a) 12 A DC MS silver system exposed for 768 h, (b) HiPIMS 200 A silver-system exposed for $1800 \mathrm{~h}$, and (c) $400 \mathrm{~A}$ HiPIMS silver system exposed for $384 \mathrm{~h}$.

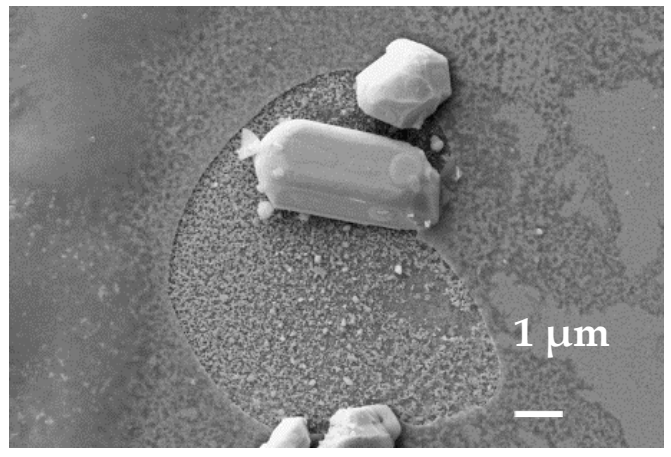

(a)

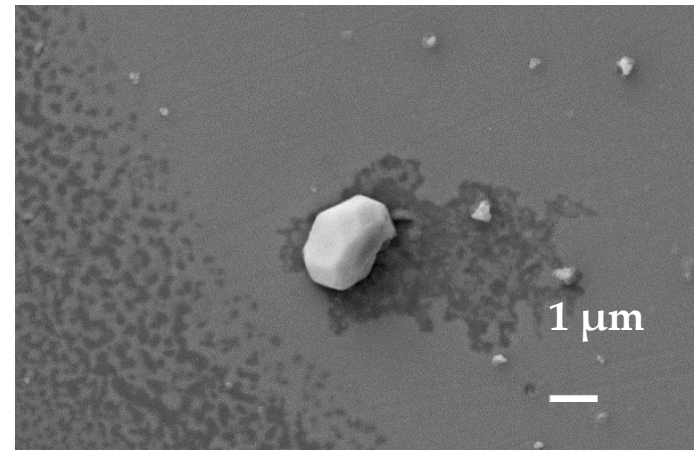

(b)

Figure 7. SEM of degradation on a protected silver system. (a) Taken from the 12 A DC MS silver system after $768 \mathrm{~h}$ at $400{ }^{\circ} \mathrm{C}$. (b) Taken from the $200 \mathrm{~A}$ HiPIMS silver system after $768 \mathrm{~h}$ at $400{ }^{\circ} \mathrm{C}$.

After $384 \mathrm{~h}$, the 400 A HiPIMS silver system sample had visually degraded to be removed from the test. The nature of the degradation, although based on silver agglomeration, appeared different from the 12 A DC MS silver-based equivalent sample. The degradation patches for the 400 A HiPIMS based sample were smaller but occurred with higher frequency. In contrast, the 12 A DC MS samples exhibited larger corrosion patches, typified by the pronounced rupturing of the top barrier layer. The $12 \mathrm{~A}$ DC MS sample remained in the oven at $400{ }^{\circ} \mathrm{C}$ further until $768 \mathrm{~h}$ but, as can be observed from the photograph Figure $6 \mathrm{a}$, showed significant degradation and was subsequently removed from the test. The HiPIMS $200 \mathrm{~A}$, however, remained visually good aside from the edge effect and scratches from the polished substrate until the end of the testing period of $1800 \mathrm{~h}$. The HiPIMS $200 \mathrm{~A}$ silver in this thin film system is thus shown to be the most durable in the $400{ }^{\circ} \mathrm{C}$ oven.

\section{Discussion}

The main aim of the work was to determine whether HiPIMS silver films, used in a protected thin film system, could improve the performance of high temperature durable reflectors in comparison to the standard DC MS equivalent. In this context, the effect of the HiPIMS mode and sputter-parameters was investigated on the resulting silver films in comparison to the 'baseline' DC MS silver used in protected silver systems.

As reported $[7,13]$, the as-deposited HiPIMS silver exhibited lower deposition rates per power density compared to DC MS. This was partially accounted for, as the HiPIMS silver grown here were 
also denser as a function of increasing peak current. The increase in density with peak current is a well-reported phenomenon [14] and can be attributed to increased energy and thus mobility of ad-atoms due to an increased amount of ions in the deposition flux [15]. Also reported [16] but not measured here is that increasing the power density and ionized flux increases compressive stress in the silver films but without an increase in lattice defects.

The resistivity of the as-deposited HiPIMS silver films decreased slightly when increasing the peak target current from $100 \mathrm{~A}$ to $200 \mathrm{~A}$ and was indeed lower (Figure 2b) than the $12 \mathrm{~A} \mathrm{DC}$ MS silver. The decrease may be due to an increase in film density as a function of peak current [17].

The resistivity of the HiPIMS silver films, however, increased significantly when increasing further to $300 \mathrm{~A}$ and then $400 \mathrm{~A}$ to values higher than that of the reference $12 \mathrm{~A} \mathrm{DC}$ MS silver. The resistivity is influenced by grain boundaries. A high number of grain boundaries and defects would reduce the efficiency of electron transport through the film, leading to a decrease in conductivity.

What was apparent was that the 200 A HiPIMS films had a similar grain size to the 12 A DC MS films. The grains had a higher degree of orientation and the film was much denser. The even denser 400 A HiPIMS film also showed a higher degree of grain orientation but a lower grain size. The film microstructure of the 400 A HiPIMS sample fits the extended Thornton model zone T [13] where the high energy leads to high surface diffusion and the formation of a dense, finer grained film with highly orientated grains. A high nucleation density, which leads to small grain size, has previously [18] been observed in HiPIMS and is enhanced by high ion currents towards the substrate surface. The increasing smaller grain size, exhibited at higher peak currents, thus increases the resistivity.

It seems that a competition between the two phenomena of the increasing density yet decreasing grain size occurred, where the highest conductivity under these sputter conditions occurred at $200 \mathrm{~A}$ in HiPIMS mode.

GIXRD and SEM showed that annealing the discrete silver films and the protected silver films led to grain growth and stronger orientation of the crystals. This, likewise, increased the conductivity for all the films presented here. Previous work [19] shows that above a certain time and temperature (and dependent on the initial thickness of the silver) the conductivity drastically reduces discrete silver films due to voiding and segregation of the silver into separated agglomerates. In this work here, the temperature and time for the relatively thick $500 \mathrm{~nm}$ silver did not exceed this point and the silver remained as a network; thus, only an increase in conductivity was measured upon annealing due to the increased grain size.

The critical parameter for the high temperature reflectors is not electrical conductivity but reflectance. The relationship between conductivity and reflectance for highly conducting metals, such as silver was derived by Drude and confirmed experimentally by Hagens-Ruben [20]. It was observed that, at higher wavelengths (lower frequencies), the optical constants of metals are similar to the values of Drude's function, where the complex refractive index is much smaller than the damping constant or extinction coefficient. This leads to high reflectance. At higher wavelengths (near infra-red to infra-red) one can thus partially correlate the increase (or decrease) in reflectance to the same physical reasons as the observed increase in conductivity (i.e., film densification) or decrease in conductivity (i.e., increase in grain boundaries due to smaller grain sizes). The as-deposited discrete silver films exhibited this correlation: the reflectivity increased with increasing film conductivity.

At higher frequencies, deviations of Drude's approach start to appear because bound electrons of the metal start to respond to the incidence of light instead of just valence band electron response. At $325 \mathrm{~nm}$, there was a drop in the reflectivity of the films which correlated to an interband transition edge at $3.8 \mathrm{eV}$ [21]. The broadening of this edge, observable in the measured reflectance spectra, with the highest current HiPIMS silver films may be correlated to defect energy states caused by, e.g., grain boundaries or other defect or impurities. Indeed, the biggest deviation in the solar reflectance between the sputtered silver samples was at this edge in the UV-visible portion of the spectrum. This is where the most gain was exhibited by the 200 A HiPIMS films. In the UV/visible portion of the spectrum absorption via surface plasmons [22], dependent on the surface geometry and size of the 
silver agglomerates on the surface, is also possible. This is particularly relevant for the discrete silver film post annealing. Clearly, from the SEM pictures of the annealed discrete silver films, the roughness increased and the surface geometry dramatically changed with annealing leading to the increased diffuse and decreased global solar reflectance.

For the protected silver film systems, the reflectance depended not only on the silver but also on the adhesion layers and barrier layers. As discussed previously in the results section, the benefits from the gain in the UV/visible portion of the spectra (around the interband transition edge) exhibited by the 200 A HiPIMS silver were not observable due to the interference effects and absorption of the metallic adhesion layer. The additional top barrier and adhesion layers were of course required as they limit the silver degradation. Thus, upon initially annealing, the protected silver film system grain growth occurred but without larger-scale agglomeration; thus, reflectance (and presumably the conductivity) increased.

Durability is defined in this context as minimized degradation in appearance and reflectance with increasing time at $400^{\circ} \mathrm{C}$. The $200 \mathrm{~A}$ HiPIMS silver system was more durable than the $12 \mathrm{~A} \mathrm{DC} \mathrm{MS,}$ whereas the 400 A HiPIMS silver system was less durable. The durability was determined by the whole film system, and it is beyond the scope of this paper to delve into the exact complex interplay between the film system and corrosion mechanism. The following aspects which affect the film stability are discussed: (1) The depositing flux during HiPIMS had a higher energy and higher ionized percentage, which would enhance the adhesion of the silver film to the substrate below, possibly improving durability. (2) The internal stress of the silver films, not measured here or even observed by a peak difference in the GIXRD, is reported [16] to be higher for the HiPIMS films, effecting the adhesion and interaction with the top barrier layer. (3) What was measured is a peak shift in the GIXRD spectra towards higher Bragg angles for all silver films in the protected film system after annealing. This shift, which was larger for the HiPIMS silver systems, implies an increase in compressive stress in the protected silver film with annealing. (4) Finally, the reduced grain size of the 400 A HiPIMS silver may be detrimental to the film stability (higher diffusion paths, increased free energy).

\section{Conclusions}

In conclusion, the 200 A HiPIMS yielded a denser layer than bulk silver films, resulting in a higher initial conductivity and reflectance than the reference DC MS sample. Annealing the silver film increased the conductivity (due to grain growth). In contrast, the reflectance decreased upon annealing due to surface structuring caused by silver agglomeration leading to unwanted light scattering and absorption by surface plasmons. The 200 A HiPIMS silver system was more durable at $400{ }^{\circ} \mathrm{C}$ than the DC MS silver equivalent system. Higher peak current HiPIMS yielded silver films which, despite the enhanced density, had smaller grains than the DC MS silver. This resulted in a decrease in conductivity and reflectance of the film. When the 400 A HiPIMS silver system was incorporated as part of a protected silver system it was less durable at $400^{\circ} \mathrm{C}$ than the DC MS silver equivalent system. Thus HiPIMS, within a lower power density range which yields denser films yet does not exhibit a reduced grain size, is beneficial for the sputtered protected silver coating technology, in particular for the application in concentrated solar power secondary reflectors.

Supplementary Materials: The following are available online at http://www.mdpi.com/2079-6412/9/10/593/s1, Table S1: Data tabulated from the GIXRD spectra for the 400 A HiPIMS, 200 A HiPIMS, and 12 A DC magnetron sputtered silver shown in Figure $4 \mathrm{a}$ as discrete films on coated-glass substrates as-deposited and after an $8 \mathrm{~h}$ $400{ }^{\circ} \mathrm{C}$ anneal. Table S2: Data tabulated from the GIXRD spectra for the 400 HiPIMS, 200 HiPIMS, and 12 A DC magnetron sputtered silver shown in Figure $4 \mathrm{~b}$ as protected silver film systems grown on coated glass substrates as deposited and after $24 \mathrm{~h} 400{ }^{\circ} \mathrm{C}$ anneal.

Author Contributions: Project conceptualization and supervision: C.H. and S.G., Layer investigation, experiment design, and analysis: S.G. and K.S., GIXRD measurement and analysis: C.W. and S.G., wrote the manuscript assisted by all other authors.

Funding: This research was funded by EU Horizon 2020 RAISELIFE, under grant agreement No. 686008.

Conflicts of Interest: The authors declare no conflict of interest. 


\section{References}

1. Fernandez-Garcia, A.; Cantos-Soto, M.E.; Roger, M.; Wieckert, C.; Hutter, C.; Martinez-Arcos, L. Durability of solar reflector materials for secondary concentrators used in csp systems. Sol. Energy Mater. Sol. Cells 2014, 130, 51-63. [CrossRef]

2. Schöttl, P.; Zoschke, T.; Frantz, C.; Gilon, Y.; Heimsath, A.; Fluri, T. In Performance Assessment of a Secondary Concentrator for Solar Tower External Receivers. In Proceedings of the 24th Solar Paces Conference, Casablanca, Morocco, 2-5 October 2018.

3. Gudmundsson, J.T.; Brenning, N.; Lundin, D.; Helmersson, U. High power impulse magnetron sputtering discharge. J. Vac. Sci. Technol. A 2012, 30, 030801. [CrossRef]

4. West, G.T.; Kelly, P.J.; Bradley, J.W. A comparison of thin silver films grown onto zinc oxide via conventional magnetron sputtering and hipims deposition. IEEE Trans. Plasma Sci. 2010, 38, 3057-3061. [CrossRef]

5. Sarakinos, K.; Wordenweber, J.; Uslu, F.; Schulz, P.; Alami, J.; Wuttig, M. The effect of the microstructure and the surface topography on the electrical properties of thin ag films deposited by high power pulsed magnetron sputtering. Surf. Coat. Technol. 2008, 202, 2323-2327. [CrossRef]

6. Schneider, T.; Vucina, T.; Hee, C.A.; Araya, C.; Moreno, C. The gemini observatory protected silver coating: Ten years in operation. Gr. Based Airborne Telesc. 2016, 9906, 990632.

7. Anders, A. Deposition rates of high power impulse magnetron sputtering: Physics and economics. J. Vac. Sci. Technol. A 2010, 28, 783-790. [CrossRef]

8. Patterson, A. The scherrer formula for x-ray particle size determination. Phys. Rev. 1939, 56, 978-982. [CrossRef]

9. Sharma, S.K.; Spitz, J. Hillock formation, hole growth and agglomeration in thin silver films. Thin Solid Films 1980, 65, 339-350. [CrossRef]

10. Sharma, S.K.; Spitz, J. Hillock growth and agglomeration in thin silver films. Thin Solid Films 1979, 61, L13-L15. [CrossRef]

11. Grunwaldt, J.D.; Atamny, F.; Gobel, U.; Baiker, A. Preparation of thin silver films on mica studied by xrd and afm. Appl. Surf. Sci. 1996, 99, 353-359. [CrossRef]

12. Georg, A. Temperatur-korrosion an spiegelschichten. In Jahrbuch Oberflächentechnik 2013; Suchentrunk, R., Ed.; Leuze Verlag: Bad Saulgau, Germany, 2013; Volume 69, pp. 221-228.

13. Anders, A. A structure zone diagram including plasma-based deposition and ion etching. Thin Solid Films 2010, 518, 4087-4090. [CrossRef]

14. Alami, J.; Bolz, S.; Sarakinos, K. High power pulsed magnetron sputtering: Fundamentals and applications. J. Alloy. Compd. 2009, 483, 530-534. [CrossRef]

15. Petrov, I.; Adibi, F.; Greene, J.E.; Hultman, L.; Sundgren, J.E. Average energy deposited per atom-A universal parameter for describing ion-assisted film growth. Appl. Phys. Lett. 1993, 63, 36-38. [CrossRef]

16. Magnfalt, D.; Abadias, G.; Sarakinos, K. Atom insertion into grain boundaries and stress generation in physically vapor deposited films. Appl. Phys. Lett. 2013, 103, 051910. [CrossRef]

17. Choi, H.M.; Choi, S.K.; Anderson, O.; Bange, K. Influence of film density on residual stress and resistivity for cu thin films deposited by bias sputtering. Thin Solid Films 2000, 358, 202-205. [CrossRef]

18. Magnfalt, D.; Elofsson, V.; Abadias, G.; Helmersson, U.; Sarakinos, K. Time-domain and energetic bombardment effects on the nucleation and coalescence of thin metal films on amorphous substrates. J. Phys. D Appl. Phys. 2013, 46, 215303. [CrossRef]

19. Kim, H.C.; Alford, T.L.; Allee, D.R. Thickness dependence on the thermal stability of silver thin films. Appl. Phys. Lett. 2002, 81, 4287-4289. [CrossRef] 
20. Silveira, F.E.M.; Kurcbart, S.M. Hagen-rubens relation beyond far-infrared region. Eur. Phys. Lett 2010, 90, 44004. [CrossRef]

21. Yang, H.H.U.; D’Archangel, J.; Sundheimer, M.L.; Tucker, E.; Boreman, G.D.; Raschke, M.B. Optical dielectric function of silver. Phys. Rev. B 2015, 91, 235137. [CrossRef]

22. Gong, J.B.; Dai, R.C.; Wang, Z.P.; Zhang, Z.M. Thickness dispersion of surface plasmon of ag nano-thin films: Determination by ellipsometry iterated with transmittance method. Sci. Rep. UK 2015, 5, 9279. [CrossRef] [PubMed]

(C) 2019 by the authors. Licensee MDPI, Basel, Switzerland. This article is an open access article distributed under the terms and conditions of the Creative Commons Attribution (CC BY) license (http://creativecommons.org/licenses/by/4.0/). 